\title{
PROPRIEDADES QUÍMICAS DE SOLO SOB REFLORESTAMENTO CILIAR APÓS 20 ANOS DE PLANTIO EM ÁREA DE CERRADO ${ }^{1}$
}

\author{
Alexandre Marques da Silva², Mario Luiz Teixeira de Moraes² e Salatiér Buzetti² $^{2}$
}

\begin{abstract}
RESUMO - As propriedades químicas do solo variam com a cultura e manejo utilizados. O trabalho teve como objetivos avaliar as propriedades químicas de solo sob reflorestamento ciliar após 20 anos de plantio em área de Cerrado localizada na Fazenda de Ensino, Pesquisa e Extensão, FEPE/UNESP, da Faculdade de Engenharia de Ilha Solteira. Foi realizada a análise química do solo (P, matéria orgânica (MO), pH, K, Ca, Mg, H+Al, $\mathrm{Al}$ e S) em 33 módulos, com três repetições em duas profundidades (0,0 - 0,20 e 0,20 - 0,40 m), com delineamento em blocos casualizados em esquema hierárquico. Os resultados indicaram que as propriedades químicas do solo sob o reflorestamento ciliar são semelhantes às propriedades do solo sem perturbação antrópica dessa região. As espécies plantadas no reflorestamento ciliar estão contribuindo com a deposição de material orgânico suficiente para que haja reciclagem de nutrientes, mantendo as propriedades químicas do solo em boas condições para que ocorra o estabelecimento da mata ciliar.
\end{abstract}

Palavras-chave: Reflorestamento ciliar, Cerrado e Mata ciliar.

\section{CHEMICAL PROPERTIES OF SOIL UNDER CILIAR REFORESTATION AFTER TWENTY YEARS OF PLANTING IN AN AREA OF SAVANNAH}

\begin{abstract}
Chemical properties of a soil change with soil management. This study had as its objective to evaluate the chemical properties of soil under riparian reforestation after twenty years of planting in an area under savannah belonging to Experimental Station, FEPE/UNESP, of Engineering College of Ilha Solteira. Chemical analysis of the soil was accomplished (P, organic matter (MO), $\mathrm{pH}, \mathrm{K}, \mathrm{Ca}, \mathrm{Mg}, \mathrm{H}+\mathrm{Al}, \mathrm{Al}$ and $\mathrm{S}$ ) in 33 modules, with 3 repetitions in two depths $(0.0-0.20$ and $0.20-0.40 \mathrm{~m})$ in a randomized block design in a hierarchical outline. The results indicated that the chemical properties of soil under riparian reforestation are similar to the properties of the soil without human disturbance in this region. The species planted in riparian reforestation are contributing to the deposition of organic material enough to have a recycling of nutrients and maintain the chemical properties of soil in good condition to have the establishment of riparian vegetation
\end{abstract}

Keywords: Ciliar reforestation, Savannah and Riparian forest.

\section{INTRODUÇÃO}

No século 19, a região de domínio de Cerrado era considerada pobre para produção agrícola, e a prática da pecuária não promovia degradação desse ambiente, porém, com a evolução tecnológica, o domínio de Cerrado passou a ser bioma altamente produtivo, e assim as práticas agropecuárias aplicadas são intensas, provocando degradação que não permite a regeneração fácil da vegetação desse ambiente. E com isso as matas ciliares não foram poupadas da destruição e são alvos de todo tipo de degradação. São áreas diretamente afetadas por construção de hidrelétricas, aberturas de estradas em regiões com topografia acidentada e implantação de culturas agrícolas e de pastagem (MARTINS, 2001).

A expressão florestas ciliares envolve todos os tipos de vegetação arbórea vinculada a margens de rios. É um conceito que se confunde com o amplo sentido de matas beiradeiras ou matas de beira-rio. Fitoecologicamente, trata-se da vegetação florestal

\footnotetext{
${ }^{1}$ Recebido em 16.08.2008 e aceito para publicação em 25.08.2010.

${ }^{2}$ Universidade Estadual Paulista Júlio de Mesquita Filho, UNESP, Brasil.E-mail:<amsilva@agr.feis.unesp.br>, <teixeira@agr.feis.unesp.br> e<sbuzetti@agr.feis.unesp.br>.
} 
às margens de cursos d'água, independentemente de sua área ou região de ocorrência e de sua composição florística. Nesse sentido, o leque de abrangência do conceito de florestas ou matas ciliares é quase total, de uma forma ou de outra, em todos os domínios morfoclimáticos e fitogeográficos do país (AB`SABER, 2004).

Para recuperação da cobertura florestal às margens dos rios em regiões de domínio de Cerrado, recomenda-se o plantio de espécies adaptadas às condições desfavoráveis de fertilidade do solo dessas regiões (DURIGAN; SILVEIRA, 1999). A deposição de serrapilheira por espécie caducifólia em matas ciliares favorece a ciclagem de nutrientes, aumentando a produção da biomassa e, com isso, o ciclo se fecha. Esse aumento de matéria orgânica melhora as condições físicas do solo.

Com a cobertura do solo pela vegetação ciliar, este se torna mais poroso e menos denso, propiciando melhor desenvolvimento das espécies arbóreas, Portanto, a intervenção do homem em determinados ambientes degradados acelera a sua recuperação. Há também diminuição na temperatura do solo, favorecendo a vida microbiana, vida essa importantíssima para o ecossistema do solo. Nas áreas onde a destruição da floresta ocorre em virtude de alterações da estrutura granulométrica do solo, ou em consequência da alteração do nível do lençol freático, se não forem tomadas as devidas providências, a restauração da vegetação nativa será praticamente impossível (REZENDE, 1998).

Os solos das matas de galeria ao longo dos cursos de água deveriam ser bem drenados na maioria dos casos. Na região do Cerrado, a densidade de drenagem do solo varia com a topografia e, consequentemente, com sua classe. Sob florestas ciliares ocorre significativa variação de solos, cujos reflexos aparecem nos diversos tipos de formação florestais, variando desde as de terrenos mais encharcados (floresta paludosa ou mata de brejo) até mais secos, onde as florestas apresentam características florísticas e fisionomias distintas, de acordo com o gradiente de umidade e influência fluvial no solo (LEÃO, 1994; JACONINE, 2004).

De modo geral, as características químicas mais importantes dos solos das matas de galeria na região de Cerrado são determinadas pelo regime hídrico do solo e das condições microclimáticas devido ao sombreamento total da superfície. Nessas condições, a decomposição de litter prossegue em uma taxa muito lenta, acumulando-se na superfície. Como consequência da decomposição da matéria orgânica, esses solos apresentam altos teores de alumínio disponível, que, entretanto, em nada impedem a nutrição mineral de árvores dessas matas (HARIDASAN, 1998).

Segundo Rodrigues et al. (2007), o solo de floresta apresenta variações na textura e fertilidade que, em parte, são refletidas pela abundância de algumas espécies. A ciclagem de nutrientes é decorrente do acúmulo da serrapilheira que acontece na floresta, e a maior fração de deposição de nutrientes está nas folhas (FERREIRA et al., 2007).

Os primeiros reflorestamentos ciliares em domínio de Cerrado foram para produção de madeira e não para recuperação, efetuada na Floresta Estadual de Assis. Utilizando várias espécies nativas e o Pinus como exótica em zona ripária, além da zona de encharcamento, têm sido bem-sucedidos. Mesmo que não favoreça a restauração da diversidade, considera-se que o plantio de Pinus pode ser a melhor alternativa para a proteção inicial rápida ao solo e aos recursos hídricos em áreas de empréstimo, solo erodido e aterros, entre outros (DURIGAN, 2005). Desse modo, este trabalho teve como objetivos avaliar as propriedades químicas de solo sob reflorestamento ciliar após 20 anos de plantio em área de Cerrado.

\section{MATERIAL E MÉTODOS}

O trabalho foi realizado no reflorestamento ciliar da Fazenda de Ensino, Pesquisa e Extensão (FEPE) da Faculdade de Engenharia de Ilha Solteira, Universidade Estadual Paulista "Julio de Mesquita Filho" (FEIS/UNESP), localizada no Município de Selvíria, MS (Figura 1).

A área da fazenda foi cedida pela Companhia Energética do Estado de São Paulo (CESP) em comodato para a UNESP, em 1977, para que fossem desenvolvidas as pesquisas agronômicas. No mesmo ano, iniciou-se o desflorestamento até a margem do rio Paraná, e a área sofreu intensiva mecanização agrícola com o plantio de arroz, e essa atividade só parou com a instalação do reflorestamento (1986).

O clima da região foi classificado como Aw, segundo o sistema de Köeppen, apresentando chuvas no verão e seca no inverno. Pela nomenclatura atual em nível de subordem, é um Latossolo Vermelho (EMBRAPA, 


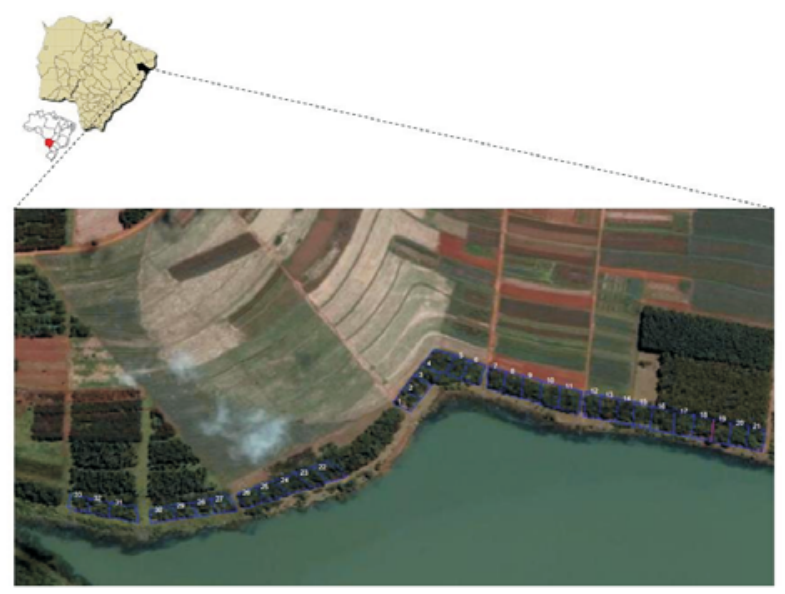

Figura 1 - Localização geográfica do reflorestamento ciliar estudado no município de Selvíria (MS).

Figure 1 - Geographical location of riparian reforestation

1999). A área de estudo está no Planalto da Bacia Sedimentar do Paraná, apresenta declives muito suaves, relevo plano e suavemente ondulado (ALVES, 2001).

O reflorestamento ciliar foi plantado nos meses de fevereiro e março de 1986, em 33 módulos compostos por 21 espécies: 1) Albizia lebbeck; 2) Holocalyx balansae; 3) Morus nigra; 4) Myroxylon peruiferum; 5) Spondias lutea; 6) Peltophorum dubium; 7) Ficus guaranitica; 8) Psidium guajava; 9) Parapiptadenia rigida; 10) Tabebuia sp.; 11) Tabebuia roseo-alba; 12) Tabebuia impetiginosa; 13) Plinia trunciflora e, ou, Alibertia edulis; 14) Jacaranda cuspidifolia; 15) Machaerium acutifolium; 16) Syzygium cumini; 17) Licania tomentosa; 18) Ceiba speciosa; 19) Koelreuteria paniculata; 20) Enterelobium contortisiliquum; e 21) Hovenia dulcis. Na Tabela 1 é apresentado o croqui de um dos módulos do reflorestamento ciliar.

O reflorestamento foi plantado com espaçamento de 2 x 3 m, sendo a área total dos módulos de 7,37 ha. As mudas para o plantio foram doadas pela CESP. O experimento possui 11 linhas de plantio, sendo a primeira e a última consideradas bordaduras, e as nove linhas centrais correspondem às três repetições com três linhas cada.

As análises químicas do solo foram obtidas a partir de amostras deformadas nas profundidades de 0,0-0,20 e 0,20-0,40 m, em cada módulo. As análises químicas do solo foram determinadas segundo metodologia descrita em Raij e Quaggio (1983). Determinaram-se fósforo, potássio, cálcio e magnésio pelo método de extração com resina trocadora de íons. A matéria orgânica foi determinada por meio do método colorimétrico e o hidrogênio mais alumínio, pela soluçãotampão SMP e pH, por solução de $\mathrm{CaCl}_{2}$ 0,01 M.

O delineamento estatístico utilizado foi o de blocos casualizados completos em esquema hierárquico. As análises estatísticas foram realizadas com o programa estatístico SISVAR (FERREIRA, 2004).

\section{RESULTADOS E DISCUSSÃO}

Nas propriedades químicas do solo analisadas houve diferenças significativas dos efeitos de profundidades dentro de módulos e de profundidades em níveis de 1 e 5\%, com exceção do pH. Quanto ao efeito de profundidades dentro de repetição, não houve diferenças estatísticas para as propriedades químicas do solo estudadas (Tabela 2).

Tabela 1 - Croqui de um módulo do reflorestamento à margem do reservatório da Usina Hidrelétrica de Ilha Solteira. Table 1 - Sketch of a module of reforestation to edge of Hydroelectrical Plant of Ilha Solteira.

\begin{tabular}{cccccccccccccccccccccc}
\hline linhas & \multicolumn{11}{c|}{ Tratamentos (espécies) } \\
\hline I (B*) & 10 & 12 & 2 & 17 & 21 & 1 & 4 & 18 & 13 & 14 & 11 & 19 & 5 & 6 & 9 & 3 & 16 & 15 & 7 & 20 & 8 \\
II & 7 & 11 & 18 & 5 & 20 & 10 & 16 & 21 & 2 & 14 & 13 & 3 & 8 & 19 & 17 & 1 & 6 & 12 & 9 & 15 & 4 \\
III & 10 & 6 & 11 & 12 & 18 & 2 & 5 & 20 & 15 & 14 & 8 & 21 & 17 & 7 & 4 & 3 & 19 & 9 & 1 & 13 & 16 \\
IV & 17 & 15 & 7 & 1 & 6 & 14 & 5 & 13 & 2 & 18 & 8 & 3 & 16 & 11 & 10 & 9 & 20 & 4 & 21 & 12 & 19 \\
V & 18 & 3 & 21 & 15 & 10 & 14 & 17 & 20 & 2 & 8 & 5 & 6 & 16 & 4 & 19 & 13 & 12 & 9 & 1 & 11 & 7 \\
VI & 2 & 10 & 8 & 5 & 12 & 21 & 11 & 6 & 16 & 15 & 20 & 3 & 4 & 19 & 14 & 17 & 7 & 9 & 18 & 13 & 1 \\
VII & 10 & 20 & 4 & 11 & 12 & 17 & 6 & 8 & 18 & 15 & 2 & 16 & 14 & 19 & 5 & 21 & 1 & 9 & 7 & 3 & 13 \\
VII & 9 & 6 & 19 & 10 & 7 & 13 & 14 & 15 & 5 & 12 & 8 & 11 & 20 & 17 & 1 & 3 & 4 & 18 & 2 & 21 & 16 \\
IX & 21 & 7 & 15 & 20 & 12 & 6 & 17 & 9 & 16 & 1 & 14 & 10 & 13 & 2 & 4 & 5 & 19 & 11 & 18 & 3 & 8 \\
X & 15 & 20 & 10 & 5 & 1 & 18 & 8 & 9 & 19 & 13 & 2 & 6 & 4 & 3 & 16 & 7 & 21 & 11 & 12 & 14 & 17 \\
XI (B) & 9 & 16 & 5 & 11 & 15 & 18 & 21 & 12 & 17 & 10 & 8 & 2 & 4 & 14 & 6 & 13 & 3 & 20 & 1 & 7 & 19 \\
\hline
\end{tabular}

* B: bordadura.

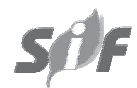

Revista Árvore, Viçosa-MG, v.35, n.1, p.97-106, 2011 
Tabela 2 - Quadrados médios, coeficientes de variação e médias das propriedades químicas do solo sob reflorestamento ciliar, aos 20 anos após o plantio, em Selvíria - MS.

Table 2 - Medium squares, variation coefficients and averages of the chemical properties of the soil under riparian reforestation, to the 20 years after the planting, in Selvíria - MS.

\begin{tabular}{|c|c|c|c|c|c|c|c|}
\hline$\overline{\text { FV }}$ & GL & $\begin{array}{c}\mathrm{P} \\
\mathrm{mg} \mathrm{dm}^{-3} \\
\end{array}$ & $\begin{array}{c}\mathrm{MO} \\
\mathrm{g} \mathrm{dm}^{-3}\end{array}$ & $\begin{array}{c}\mathrm{pH} \\
\mathrm{CaCl}_{2} \\
\end{array}$ & $\mathrm{~K}$ & $\begin{array}{c}\mathrm{Ca} \\
\mathrm{mmol}_{\mathrm{c}} \mathrm{dm}^{-3}\end{array}$ & $\mathrm{Mg}$ \\
\hline Repetição (Profundidade) & 4 & $1^{\mathrm{ns}}$ & $3^{\text {ns }}$ & $0,05^{\mathrm{ns}}$ & $0,01^{\mathrm{ns}}$ & $11^{\mathrm{ns}}$ & $4^{\mathrm{ns}}$ \\
\hline Módulo (Profundidade) & 64 & $23 * *$ & $14 * *$ & $0,12 * *$ & $0,66 * *$ & $67 * *$ & $17 * *$ \\
\hline Profundidade & 1 & $42 * *$ & $2879 * *$ & 0,05 ns & $14,35 * *$ & $1178 * *$ & $185 * *$ \\
\hline $\begin{array}{l}\text { Erro } \\
\text { CV (\%) } \\
\text { Média }\end{array}$ & 128 & $\begin{array}{c}1 \\
17,86 \\
5\end{array}$ & $\begin{array}{c}6 \\
12,01 \\
20\end{array}$ & $\begin{array}{c}0,02 \\
3,38 \\
4,3\end{array}$ & $\begin{array}{c}0,14 \\
46,22 \\
0,8\end{array}$ & $\begin{array}{c}12 \\
43,44 \\
8\end{array}$ & $\begin{array}{c}3 \\
33,59 \\
5\end{array}$ \\
\hline \multirow[t]{2}{*}{ FV } & GL & $\mathrm{H}+\mathrm{Al}$ & $\mathrm{Al}$ & SB & $\mathrm{T}$ & $\mathrm{V}$ & $\mathrm{S}$ \\
\hline & & \multicolumn{4}{|c|}{$\mathrm{mmol}_{\mathrm{c}} \mathrm{dm}^{-3}$} & $\%$ & $\mathrm{mg} \mathrm{dm}^{-3}$ \\
\hline Repetição (Profundidade) & 4 & $68^{\text {ns }}$ & $2^{\text {ns }}$ & $29^{\text {ns }}$ & $86^{\mathrm{ns}}$ & $50^{\text {ns }}$ & $0^{\mathrm{ns}}$ \\
\hline Módulo (Profundidade) & 64 & $360 * *$ & $31 * *$ & $153 * *$ & $255 * *$ & $275 * *$ & $15 * *$ \\
\hline Profundidade & 1 & $9136 * *$ & $26 * *$ & $3429 * *$ & $23914 * *$ & $41 * *$ & $184 * *$ \\
\hline $\begin{array}{l}\text { Erro } \\
\text { CV (\%) } \\
\text { Média }\end{array}$ & 128 & $\begin{array}{c}47 \\
13,23 \\
52\end{array}$ & $\begin{array}{c}3 \\
37,88 \\
4\end{array}$ & $\begin{array}{c}25 \\
36,87 \\
14\end{array}$ & $\begin{array}{c}54 \\
11,23 \\
66\end{array}$ & $\begin{array}{c}42 \\
31,86 \\
20\end{array}$ & $\begin{array}{c}4 \\
57,20 \\
3\end{array}$ \\
\hline
\end{tabular}

FV: fonte de variação; GL: graus de liberdade; P: fósforo; MO: matéria orgânica; K: potássio; Ca: cálcio; Mg: magnésio; H+Al: hidrogênio+alumínio; Al: alumínio; SB: soma de bases; T: capacidade de troca catiônica; V: saturação por bases e S: enxofre. ns: não significativo; *: significativo a $5 \% \mathrm{e}^{* *}$ : significativo a $1 \%$.

As médias dos teores de fósforo, potássio e enxofre foram consideradas de baixa magnitude. Já a média para acidez foi muito alta. Os teores de cálcio e magnésio estão em níveis alto e médio, respectivamente. E a soma de bases (SB) está muito baixa, conforme Raij et al. (1996).

O teor de matéria orgânica (MO) apresenta-se médio, segundo Lopes (1984), que, estudando os solos sob Cerrado, verificou que a maioria dos níveis médios dos valores para essa propriedade se encontrava entre 15 e $30 \mathrm{~g} \mathrm{dm}^{-3}$.

Pelo teste de Scott e Knott, o conteúdo médio do fósforo foi agrupado em cinco classes na profundidade de 0,0-0,20 m e em seis classes na profundidade de 0,20-0,40 m, demonstrando heterogeneidade para esse elemento nas duas profundidades estudadas (Tabela 3). Essa heterogeneidade de fósforo entre os módulos pode estar associada com o deslocamento dos macronutrientes das áreas agrícolas para o reflorestamento ciliar, visto que os maiores valores encontrados estão justamente nos módulos que fazem limites com essas áreas. Como o fósforo é pouco móvel no solo, através da lixiviação é possível que o processo erosivo tenha influenciado esse movimento. A maior disponibilidade dos nutrientes faz que a floresta produza mais massa verde, que é depositada no solo, formando uma camada de matéria orgânica. Pinheiro et al. (2004) estudaram remanescente de mata ciliar encontrando teores de fósforo de $24,00 \mathrm{mg} \cdot \mathrm{dm}^{-3}$, associando essa vegetação com micorrizas, liberando hidrogênio e ácidos orgânicos e solubilizando fósforo inorgânico. De acordo com Raij et al. (1996), os valores médios de fósforo encontrados nas profundidades estudadas variaram de 0 a $10 \mathrm{mg} \mathrm{dm}^{-3}$ e de muito baixos a baixos.

Cavenage (1996) estudou as propriedades químicas de um Latossolo Vermelho-Escuro sob diferentes vegetações, incluindo a área de reflorestamento ciliar aos 10 anos após o plantio à margem do reservatório de Ilha Solteira, nas profundidades de $0,0-0,10 ; 0,10-0,20$; e $0,20-0,40 \mathrm{~m}$, encontrando valores para fósforo de 5,30; 3,90; e $1,80 \mathrm{mg} \mathrm{dm}^{-3}$. Tais valores são menores que o deste trabalho, observando-se, assim, aumento nesse elemento com o decorrer dos anos. Cavalcante (1999) constatou valor médio de fósforo de $5,6 \mathrm{mg} \mathrm{dm}^{-3}$ na profundidade de 0,0-0,20 m, enquanto Souza (2000) obteve valores de 4,05 e $1,5 \mathrm{mg} \mathrm{dm}^{-3}$ nas profundidades de 0,0-0,20 e 0,20-0,40 m, em estudos realizados em área natural do Cerrado na FEPE/UNESP de Ilha Solteira, local deste estudo.

De acordo com Lopes (1984), o teor de matéria orgânica neste trabalho é considerado médio, com os valores variando de 20 a $30 \mathrm{~g} \mathrm{dm}^{-3}$ na profundidade de $0,0-0,20 \mathrm{~m}$ e de 13 a $21 \mathrm{~g} \mathrm{dm}^{-3}$, na profundidade de 0,20-0,40 m (Tabela 3). 
Tabela 3 -Valores médios do desdobramento de módulos dentro de profundidades para as propriedades químicas do solo sob reflorestamento ciliar, aos 20 anos após o plantio, em Selvíria-MS.

Table 3 - Medium values of the unfolding of modules inside of depths for the chemical properties of the soil under riparian reforestation, to the 20 years after the planting, in Selvíria-MS.

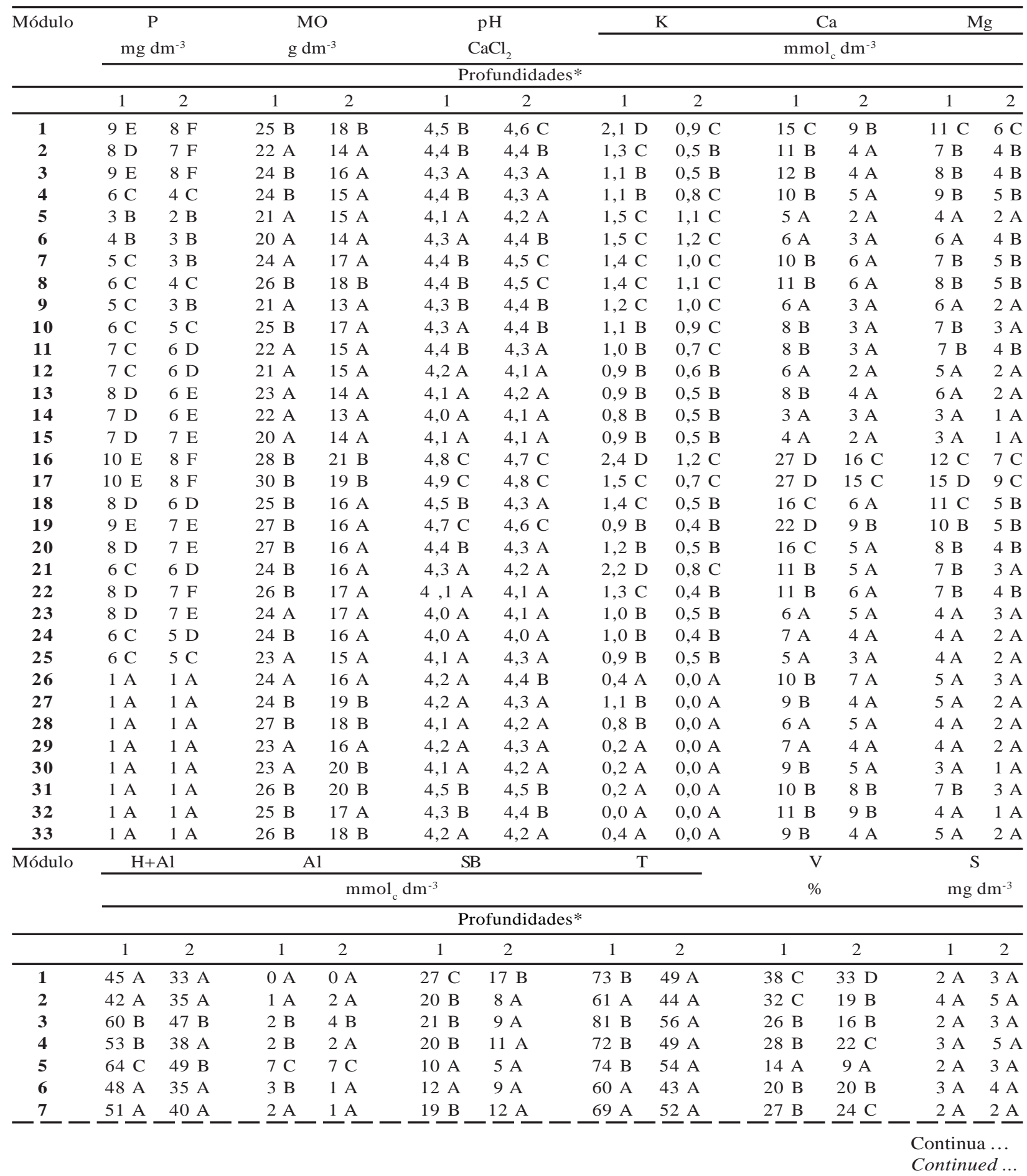


Tabela 3 - Cont.

\begin{tabular}{|c|c|c|c|c|c|c|c|c|c|c|c|c|}
\hline 8 & $51 \mathrm{~A}$ & $36 \mathrm{~A}$ & $1 \mathrm{~A}$ & $0 \mathrm{~A}$ & $20 \mathrm{~B}$ & $12 \mathrm{~A}$ & $71 \mathrm{~B}$ & $48 \mathrm{~A}$ & $28 \mathrm{~B}$ & $25 \mathrm{C}$ & $2 \mathrm{~A}$ & $2 \mathrm{~A}$ \\
\hline 9 & $45 \mathrm{~A}$ & $34 \mathrm{~A}$ & $2 \mathrm{~A}$ & $0 \mathrm{~A}$ & $13 \mathrm{~A}$ & $6 \mathrm{~A}$ & $58 \mathrm{~A}$ & $40 \mathrm{~A}$ & $22 \mathrm{~B}$ & $16 \mathrm{~B}$ & $2 \mathrm{~A}$ & $3 \mathrm{~A}$ \\
\hline 10 & $50 \mathrm{~A}$ & $41 \mathrm{~A}$ & $1 \mathrm{~A}$ & 2 B & $17 \mathrm{~B}$ & $7 \mathrm{~A}$ & $67 \mathrm{~A}$ & $47 \mathrm{~A}$ & $25 \mathrm{~B}$ & $13 \mathrm{~A}$ & $2 \mathrm{~A}$ & $3 \mathrm{~A}$ \\
\hline 11 & $47 \mathrm{~A}$ & $39 \mathrm{~A}$ & $2 \mathrm{~B}$ & 3 B & $16 \mathrm{~B}$ & 7 A & $63 \mathrm{~A}$ & $46 \mathrm{~A}$ & $25 \mathrm{~B}$ & $16 \mathrm{~B}$ & 2 A & $4 \mathrm{~A}$ \\
\hline 12 & $56 \mathrm{~B}$ & $46 \mathrm{~B}$ & $5 \mathrm{~B}$ & $4 \mathrm{~B}$ & $11 \mathrm{~A}$ & $5 \mathrm{~A}$ & $67 \mathrm{~A}$ & $50 \mathrm{~A}$ & $17 \mathrm{~A}$ & $9 \mathrm{~A}$ & $3 \mathrm{~A}$ & $4 \mathrm{~A}$ \\
\hline 13 & $59 \mathrm{~B}$ & $40 \mathrm{~A}$ & $3 \mathrm{~B}$ & 3 B & $15 \mathrm{~B}$ & $6 \mathrm{~A}$ & $74 \mathrm{~B}$ & $47 \mathrm{~A}$ & $21 \mathrm{~B}$ & $14 \mathrm{~A}$ & $2 \mathrm{~A}$ & $3 \mathrm{~A}$ \\
\hline 14 & $65 \mathrm{C}$ & 49 B & $8 \mathrm{C}$ & $6 \mathrm{C}$ & $7 \mathrm{~A}$ & $4 \mathrm{~A}$ & $71 \mathrm{~B}$ & $53 \mathrm{~A}$ & $10 \mathrm{~A}$ & $8 \mathrm{~A}$ & $3 \mathrm{~A}$ & $2 \mathrm{~A}$ \\
\hline 15 & $60 \mathrm{~B}$ & $48 \mathrm{~B}$ & $7 \mathrm{C}$ & 6 C & $8 \mathrm{~A}$ & $4 \mathrm{~A}$ & $68 \mathrm{~A}$ & $52 \mathrm{~A}$ & $11 \mathrm{~A}$ & $7 \mathrm{~A}$ & $2 \mathrm{~A}$ & $4 \mathrm{~A}$ \\
\hline 16 & $43 \mathrm{~A}$ & $36 \mathrm{~A}$ & $0 \mathrm{~A}$ & $1 \mathrm{~A}$ & $41 \mathrm{D}$ & $25 \mathrm{C}$ & $84 \mathrm{C}$ & $61 \mathrm{~B}$ & $48 \mathrm{D}$ & $38 \mathrm{D}$ & $2 \mathrm{~A}$ & $3 \mathrm{~A}$ \\
\hline 17 & $42 \mathrm{~A}$ & $35 \mathrm{~A}$ & $0 \mathrm{~A}$ & $0 \mathrm{~A}$ & $44 \mathrm{D}$ & $25 \mathrm{C}$ & $86 \mathrm{C}$ & $60 \mathrm{~B}$ & $51 \mathrm{D}$ & $40 \mathrm{D}$ & $2 \mathrm{~A}$ & $3 \mathrm{~A}$ \\
\hline 18 & $50 \mathrm{~A}$ & $48 \mathrm{~B}$ & $1 \mathrm{~A}$ & 2 A & $28 \mathrm{C}$ & $11 \mathrm{~A}$ & $79 \mathrm{~B}$ & 59 B & $37 \mathrm{C}$ & 19 B & $3 \mathrm{~A}$ & $3 \mathrm{~A}$ \\
\hline 19 & $48 \mathrm{~A}$ & $37 \mathrm{~A}$ & $0 \mathrm{~A}$ & $2 \mathrm{~A}$ & $33 \mathrm{C}$ & $14 \mathrm{~A}$ & $80 \mathrm{~B}$ & $51 \mathrm{~A}$ & $40 \mathrm{C}$ & $27 \mathrm{C}$ & $2 \mathrm{~A}$ & $4 \mathrm{~A}$ \\
\hline 20 & $50 \mathrm{~A}$ & $41 \mathrm{~A}$ & $2 \mathrm{~B}$ & $5 \mathrm{C}$ & $26 \mathrm{C}$ & $9 \mathrm{~A}$ & $76 \mathrm{~B}$ & $51 \mathrm{~A}$ & $34 \mathrm{C}$ & $18 \mathrm{~B}$ & $2 \mathrm{~A}$ & $4 \mathrm{~A}$ \\
\hline 21 & $55 \mathrm{~B}$ & $47 \mathrm{~B}$ & $5 \mathrm{~B}$ & $6 \mathrm{C}$ & $20 \mathrm{~B}$ & $8 \mathrm{~A}$ & $75 \mathrm{~B}$ & $55 \mathrm{~A}$ & $26 \mathrm{~B}$ & $15 \mathrm{~B}$ & $2 \mathrm{~A}$ & $4 \mathrm{~A}$ \\
\hline 22 & $75 \mathrm{C}$ & $56 \mathrm{C}$ & $8 \mathrm{C}$ & $7 \mathrm{D}$ & 19 B & $11 \mathrm{~A}$ & $94 \mathrm{C}$ & $67 \mathrm{~B}$ & $20 \mathrm{~B}$ & $17 \mathrm{~B}$ & $2 \mathrm{~A}$ & $3 \mathrm{~A}$ \\
\hline 23 & $87 \mathrm{D}$ & $62 \mathrm{C}$ & $11 \mathrm{D}$ & $9 \mathrm{D}$ & $10 \mathrm{~A}$ & $8 \mathrm{~A}$ & $97 \mathrm{C}$ & $70 \mathrm{~B}$ & $11 \mathrm{~A}$ & $11 \mathrm{~A}$ & $2 \mathrm{~A}$ & $6 \mathrm{~A}$ \\
\hline 24 & $83 \mathrm{D}$ & $59 \mathrm{C}$ & $11 \mathrm{D}$ & $10 \mathrm{D}$ & $12 \mathrm{~A}$ & $6 \mathrm{~A}$ & $95 \mathrm{C}$ & $65 \mathrm{~B}$ & $13 \mathrm{~A}$ & $10 \mathrm{~A}$ & $3 \mathrm{~A}$ & 8 B \\
\hline 25 & $66 \mathrm{C}$ & $44 \mathrm{~A}$ & $8 \mathrm{C}$ & $5 \mathrm{C}$ & $10 \mathrm{~A}$ & $6 \mathrm{~A}$ & $75 \mathrm{~B}$ & $50 \mathrm{~A}$ & $13 \mathrm{~A}$ & $11 \mathrm{~A}$ & $2 \mathrm{~A}$ & $10 \mathrm{~B}$ \\
\hline 26 & $65 \mathrm{C}$ & $42 \mathrm{~A}$ & $7 \mathrm{C}$ & 3 B & $14 \mathrm{~A}$ & $11 \mathrm{~A}$ & 79 B & $54 \mathrm{~A}$ & $17 \mathrm{~A}$ & $21 \mathrm{~B}$ & $3 \mathrm{~A}$ & $13 \mathrm{C}$ \\
\hline 27 & $64 \mathrm{C}$ & $52 \mathrm{~B}$ & $8 \mathrm{C}$ & 6 C & $15 \mathrm{~B}$ & $5 \mathrm{~A}$ & $79 \mathrm{~B}$ & $58 \mathrm{~B}$ & 19 B & 9 A & $2 \mathrm{~A}$ & $1 \mathrm{~A}$ \\
\hline 28 & $86 \mathrm{D}$ & $61 \mathrm{C}$ & $10 \mathrm{D}$ & $8 \mathrm{D}$ & $11 \mathrm{~A}$ & $7 \mathrm{~A}$ & $97 \mathrm{C}$ & $68 \mathrm{~B}$ & $11 \mathrm{~A}$ & $10 \mathrm{~A}$ & $2 \mathrm{~A}$ & $2 \mathrm{~A}$ \\
\hline 29 & $67 \mathrm{C}$ & $51 \mathrm{~B}$ & $8 \mathrm{C}$ & $6 \mathrm{C}$ & $11 \mathrm{~A}$ & $5 \mathrm{~A}$ & $78 \mathrm{~B}$ & $56 \mathrm{~A}$ & $15 \mathrm{~A}$ & $10 \mathrm{~A}$ & $2 \mathrm{~A}$ & $1 \mathrm{~A}$ \\
\hline 30 & $80 \mathrm{D}$ & $64 \mathrm{C}$ & $10 \mathrm{D}$ & $8 \mathrm{D}$ & $11 \mathrm{~A}$ & 7 A & $91 \mathrm{C}$ & $71 \mathrm{~B}$ & $13 \mathrm{~A}$ & $10 \mathrm{~A}$ & $1 \mathrm{~A}$ & $3 \mathrm{~A}$ \\
\hline 31 & $57 \mathrm{~B}$ & $44 \mathrm{~A}$ & $3 \mathrm{~B}$ & $2 \mathrm{~A}$ & $16 \mathrm{~B}$ & $12 \mathrm{~A}$ & $73 \mathrm{~B}$ & $56 \mathrm{~A}$ & $22 \mathrm{~B}$ & $21 \mathrm{~B}$ & $3 \mathrm{~A}$ & $7 \mathrm{~A}$ \\
\hline 32 & $57 \mathrm{~B}$ & $47 \mathrm{~B}$ & $7 \mathrm{C}$ & $4 \mathrm{~B}$ & $15 \mathrm{~B}$ & $10 \mathrm{~A}$ & $71 \mathrm{~B}$ & $57 \mathrm{~A}$ & $20 \mathrm{~B}$ & $17 \mathrm{~B}$ & $5 \mathrm{~A}$ & $15 \mathrm{C}$ \\
\hline 33 & $73 \mathrm{C}$ & $56 \mathrm{C}$ & $8 \mathrm{C}$ & $7 \mathrm{C}$ & $15 \mathrm{~B}$ & $6 \mathrm{~A}$ & $88 \mathrm{C}$ & $63 \mathrm{~B}$ & $17 \mathrm{~A}$ & $10 \mathrm{~A}$ & $2 \mathrm{~A}$ & $3 \mathrm{~A}$ \\
\hline
\end{tabular}

* 1: 0-20 cm; 2: 20-40 cm. P: fósforo; MO: matéria orgânica; K: potássio; Ca: cálcio; Mg: magnésio. Médias não seguidas por mesma letra diferem entre si pelo teste de Scott e Knott a 5\% de probabilidade.

* 1: 0-20 cm; 2: 20-40 cm. H+Al: hidrogênio+alumínio; Al: alumínio; SB: soma de bases; T: capacidade de troca catiônica; V: saturação por bases; e S: enxofre. Médias não seguidas por mesma letra diferem entre si, pelo teste de Scott e Knott a $5 \%$ de probabilidade.

Em estudo realizado na FEPE/UNESP de Ilha Solteira avaliando as alterações das propriedades físicas de um Latossolo Vermelho-Escuro sob diferentes culturas, Cavenage et al. (1999) encontraram valores de matéria orgânica em área de Cerrado natural de 30,5 e 14,4 $\mathrm{g} \mathrm{dm}^{-3}$, nas profundidades de 0,0-0,20 e 0,20-0,40 m, e nessas mesmas profundidades os valores nesse reflorestamento ciliar foram de 26,7 e 16,4 $\mathrm{g} \mathrm{dm}^{-3}$. Os valores de matéria orgânica da área natural de Cerrado encontrados por Cavenage et al. (1999) foram maiores que o deste trabalho, na profundidade de $0,0-0,20 \mathrm{~m}$, menores na profundidade de 0,20-0,40 m e semelhantes com os valores encontrados nessa mesma área de estudo pelo mesmo autor. Portanto, a deposição de matéria orgânica não mudou no decorrer desses anos, mesmo com a morte de algumas árvores. Isso indica que o reflorestamento está mantendo a ciclagem de nutrientes dando condições para o estabelecimento do sub-bosque dessas plantas.
Bertalot et al. (2004) estudaram a produção de biomassa, a concentração e o acúmulo de nutrientes de quatro espécies de leguminosas nas quatro estações do ano, concluindo que, quanto maior a produção da serrapilheira, maior a quantidade de $\mathrm{Ca}, \mathrm{K}, \mathrm{Mg}, \mathrm{P}$ e S.

Os valores médios de $\mathrm{pH}\left(\mathrm{CaCl}_{2}\right)$ foram de $4,0 \mathrm{a}$ 4,9 nas profundidades dentro dos módulos estudados (Tabela 3). Valores semelhantes foram verificados por Cavenage (1996) de 4,6 a 4,7 em reflorestamento ciliar. Silva (2002) e Pinheiro et al. (2004) estudaram o solo sob mata ciliar e encontraram valores de $\mathrm{pH}\left(\mathrm{CaCl}_{2}\right)$ de 3,8 e 4,6, respectivamente, mostrando que esses solos sob mata ciliar são naturalmente ácidos. Para a área natural de Cerrado foram encontrados valores de $\mathrm{pH}\left(\mathrm{CaCl}_{2}\right)$ de 3,9 a 4,7 (CAVENAGE et al., 1999; CAVALCANTE, 1999; SOUZA, 2000), indicando que a acidez desse solo é naturalmente alta. 
Segundo Gonçalves (1995), as espécies das classes ecológicas denominadas secundárias e clímax são bem mais exigentes nutricionalmente do que as pioneiras, em que a faixa ideal de $\mathrm{pH}\left(\mathrm{CaCl}_{2}\right)$ varia de 5,5 a 6,0. Portanto, as espécies plantadas no reflorestamento ciliar estão bem adaptadas às condições de acidez desse solo, por ser a maioria de classe secundária e por não serem nativas da região.

A variação do potássio provavelmente está associada à fácil lixiviação desseelemento pelaágua da chuva. Percebeu-se isso ocorrendo nos módulos que não eram vizinhos das áreas agrícolas, os quais apresentaram os menores valores (Tabela 3). Esses módulos que apresentaram os menores valores de potássio são de 26 a 33, que eram vizinhos do florestamento de Pinus e não receberam adubação química. Os demais módulos eram vizinhos de áreas agrícolas adubadas todos os anos.

Pelo teste de Scott e Knott, os valores médios de potássio foram agrupados em quatro e três classes de médias, nas profundidades estudadas. Ocorreu heterogeneidade quanto à contaminação desse elemento, e essas diferenças foram justamente devidas ao entorno do reflorestamento ciliar, que sofreu lixiviação desses elementos. Tais valores estão variando de 0,0 a $2,4 \mathrm{mmol}_{\mathrm{c}} \mathrm{dm}^{-3}$, na profundidade de $0,0-0,20 \mathrm{~m}$ e de 0,0 a 1,2 $\mathrm{mmol}_{\mathrm{c}} \mathrm{dm}^{-3}$, na profundidade de 0,20-0,40 m. No entanto, o potássio não está sendo lixiviado para o subsolo, talvez porque a quantidade desse elemento que o reflorestamento ciliar recebe é suficiente apenas para suprir as necessidades das espécies ali plantadas. Não há interpretação desse elemento para espécies arbóreas. Segundo Raij et al. (1996), esse elemento encontrava-se na profundidade de 0,0-0,20 m como muito baixa a média; e na profundidade de 0,20-0,40 m, de muito baixa a baixa.

Se comparado com o trabalho de Cavenage et al. (1999), houve aumento desse elemento no reflorestamento ciliar, com exceções dos módulos limitantes com florestamento de Pinus e Eucalyptus (10 a 15 e 27 a 33). Em área natural, esse elemento se encontrava em valores inferiores ao deste trabalho (CAVENAGE et al., 1999; CAVALCANTE, 1999; SOUZA, 2000).

O que está acontecendo com o potássio também é evidente com os teores de cálcio e magnésio. Os módulos vizinhos às áreas agrícolas apresentam os maiores valores para esses elementos (Tabela 3). Na profundidade de 0,0-0,20 m, têm-se os maiores valores para cálcio nos módulos de 1 a 4, 7, 8 e 16 a 22, o que também ocorre com o magnésio. Existe heterogeneidade desses elementos, pois foram divididos em quatro classes de médias na primeira profundidade e em três na segunda profundidade estudada, pelo teste de Scott e Knott. Isso apesar de que, na profundidade de 0,20-0,40 m, apenas os módulos 16 e 17 apresentaram os maiores valores para cálcio.

Mesmo os módulos que não fazem limites com as áreas agrícolas (10 a 15 e 27 a 33) apresentam valores médios de cálcio e magnésio suficientes para manter o desenvolvimento das plantas ali instaladas; isso na profundidade de $0,0-0,20 \mathrm{~m}$. Tal fato indica que o reflorestamento ciliar está cumprindo o seu papel de ciclagem dos nutrientes.

Os valores de cálcio e magnésio no subsolo, ou seja, na profundidade de 0,20-0,40 m, apresentaram valores menores do que na profundidade de $0,0-0,20 \mathrm{~m}$, condição essa que ocorre naturalmente nos solos. $\mathrm{O}$ estudo do cálcio em profundidade, associado com o alumínio, serve para diagnosticar possíveis condições desfavoráveis ao desenvolvimento radicular das plantas menos tolerantes à acidez. Valores de cálcio menores de $4 \mathrm{mmol}_{\mathrm{c}} \mathrm{dm}^{-3}$ e alumínio maior que $5 \mathrm{mmol}_{\mathrm{c}} \mathrm{dm}^{-3}$ (RAIJ et al., 1996) podem causar toxidade às plantas.

Nota-se que os módulos 1, 16, 17, 19, 31 e 32, na profundidade de 0,20-0,40 m, têm valores médios de cálcio acima de $8 \mathrm{mmol}_{\mathrm{c}} \mathrm{dm}^{-3}$ evalores de alumínio (Tabela 2) menores que $4 \mathrm{mmol}_{\mathrm{c}} \mathrm{dm}^{-3}$, o que dá condições para o desenvolvimento radicular das plantas. Os demais módulos apresentam condições limitantes ao estabelecimento de plantas que não toleram valores altos de alumínio.

A área natural estudada por Cavalcante (1999) e Souza (2000) apresentou valores inferiores de cálcio e magnésio, se comparados com os valores aqui demonstrados. Mas Cavenage et al. (1999), em área natural e no reflorestamento ciliar, encontraram valores semelhantes ao deste trabalho.

Os módulos 5, 14, 15, 22 a 30, 32 e 33 apresentaram

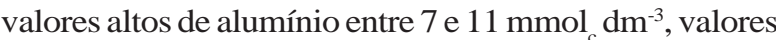
esses considerados altos para o desenvolvimento de plantas, pois nesses níveis pode causar toxidade (Tabela 3). Os demais módulos apresentaram valores que favorece o estabelecimento de plantas. Esses valores altos de alumínio podem ser a causa da baixa percentagem de sobrevivência das plantas ali

Revista Árvore, Viçosa-MG, v.35, n.1, p.97-106, 2011 
introduzidas, mas essas espécies se apresentaram bem adaptadas a tais condições, por terem bom desenvolvimento nesse local.

O solo natural dessa região apresentou valores altos de alumínio(CAVENAGE etal., 1999; CAVALCANTE, 1999; SOUZA, 2000). Cavenage et al. (1999) encontraram valores acima dos aqui apresentados, mostrando a contribuição do reflorestamento ciliar no decorrer dos anos em melhorar as condições das propriedades químicas desse solo pela deposição de material orgânico e pela ciclagem de nutrientes que está acontecendo nessa área.

Os valores de enxofre na profundidade de 0,0-0,20 m não diferiram estatisticamente entre os módulos estudados (Tabela 3). Os maiores teores de enxofre foram apresentados no subsolo, ou seja, na profundidade de 0,20-0,40 m, nos módulos 26 e 32.

Na Tabela 4 estão apresentados os valores médios das profundidades estudadas em função das propriedades químicas do solo. Na maioria dos caracteres ocorreu diminuição nos valores de acordo com a profundidade, à exceção do $\mathrm{pH}$, que não diferiu entre

Tabela 4 - Valores médios das profundidades estudadas em função das propriedades químicas do solo sob reflorestamento ciliar, aos 20 anos após o plantio, em Selvíria, MS.

Table 4-Medium values for the depths studied as a function of the chemical properties of the soil under riparian reforestation, to the 20 years after the planting, in Selvíria, MS.

\begin{tabular}{|c|c|c|c|c|}
\hline \multirow[t]{2}{*}{ Caracteres } & \multicolumn{4}{|c|}{ Profundidade* } \\
\hline & & 1 & 2 & \\
\hline $\mathrm{P}\left(\mathrm{mg} \mathrm{dm} \mathrm{dm}^{-3}\right)$ & 6 & $\mathrm{~B}$ & 5 & A \\
\hline $\mathrm{MO}\left(\mathrm{g} \mathrm{dm}^{-3}\right)$ & 24 & $\mathrm{~B}$ & 16 & A \\
\hline $\mathrm{pH}\left(\mathrm{CaCl}_{2}\right)$ & 4,3 & A & 4,3 & A \\
\hline $\mathrm{K}\left(\mathrm{mmol}_{\mathrm{c}} \mathrm{dm}^{-3}\right)$ & 1,1 & $\mathrm{~B}$ & 0,5 & A \\
\hline $\mathrm{Ca}\left(\mathrm{mmol}_{\mathrm{c}} \mathrm{dm}^{-3}\right)$ & 10 & $\mathrm{~B}$ & 5 & A \\
\hline $\mathrm{MG}\left(\mathrm{mmol}_{\mathrm{c}} \mathrm{dm}^{-3}\right)$ & 6 & $\mathrm{~B}$ & 3 & A \\
\hline $\mathrm{H}+\mathrm{Al}\left(\mathrm{mmol}_{\mathrm{c}} \mathrm{dm}^{-3}\right)$ & 59 & $\mathrm{~B}$ & 45 & A \\
\hline $\mathrm{Al}\left(\mathrm{mmol}_{\mathrm{c}} \mathrm{dm}^{-3}\right)$ & 5 & $\mathrm{~B}$ & 4 & A \\
\hline $\mathrm{SB}\left(\mathrm{mmol}_{\mathrm{c}} \mathrm{dm}^{-3}\right)$ & 18 & $\mathrm{~B}$ & 9 & A \\
\hline $\mathrm{T}\left(\mathrm{mmol}_{\mathrm{c}} \mathrm{dm}^{-3}\right)$ & 77 & B & 55 & A \\
\hline V (\%) & 23 & $\mathrm{~B}$ & 17 & A \\
\hline $\mathrm{S}\left(\mathrm{mg} \mathrm{dm} \mathrm{m}^{-3}\right)$ & 2 & A & 4 & $\mathrm{~B}$ \\
\hline
\end{tabular}

* 1: 0-20 cm; 2: 20-40 cm. P: fósforo; MO: matéria orgânica; K: potássio; Ca: cálcio; Mg: magnésio; H+Al: hidrogênio+alumínio; Al: alumínio; SB: soma de bases; T: capacidade de troca catiônica; V: saturação por bases; e S: enxofre. Médias não seguidas por mesma letra diferem entre si, pelo teste de Scott e Knott a $5 \%$ de probabilidade. as profundidades estudadas e para o enxofre, que ocorreu o inverso, já que o sulfato tende a se acumular no subsolo.

É possível perceber que, a partir dos valores apresentados na Tabela 4, mesmo sendo um solo ácido, os valores de macronutrientes são suficientes para a manutenção das condições nutricionais para que haja o restabelecimento das espécies nativas que ali ocorrem e a manutenção do banco de sementes e plântulas.

\section{CONCLUSÕES}

As propriedades químicas do solo sob o reflorestamento ciliar são semelhantes às propriedades do solo sem perturbação antrópica dessa região.

As espécies plantadas no reflorestamento ciliar estão contribuindo com a deposição de material orgânico suficiente para que haja reciclagem de nutrientes e mantendo as propriedades químicas desse solo em boas condições, para que ocorra o estabelecimento da mata ciliar.

\section{AGRADECIMENTOS}

À Fundação para o Desenvolvimento da UNESP - FUNDUNESP, pelo auxílio financeiro para o desenvolvimento da pesquisa.

\section{REFERÊNCIAS}

AB'SABER, A. N. O suporte geoecológico das florestas beiradeiras (ciliares). In: RODRIGUES, R. R.; LEITÃO FILHO, H. F. (Eds.). Matas ciliares: conservação e recuperação. 2.ed. São Paulo: Universidade de São Paulo, 2004. p.15-25.

ALVES, M. C. Recuperação do subsolo de um latossolo vermelho usado para terrapleno e fundação da Usina Hidrelétrica de Ilha Solteira-SP. 2001. 83f. Tese (Livre-Docente) - Faculdade de Engenharia de Ilha Solteira, Universidade Estadual Paulista, Ilha Solteira, 2001.

BERTALOT, M. J. A. et al. Retorno de nutrientes ao solo via deposição de serapilheira de quatro espécies leguminosa arbóreas na região de Botucatu - São Paulo, Brasil. Scientia Forestalis, n.65, p.219-227, 2004. 


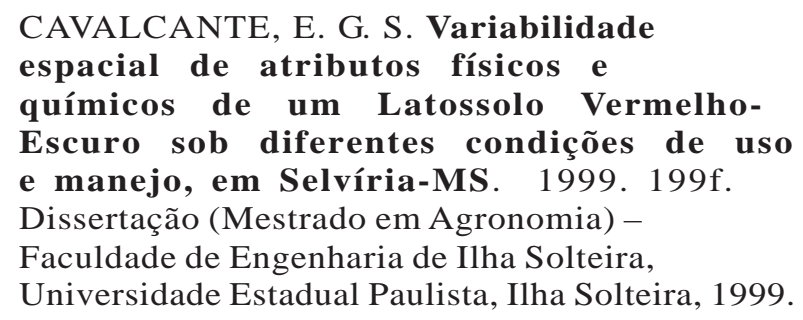

CAVENAGE, A. et al. Alterações das propriedades físicas de um Latossolo VermelhoEscuro sob diferentes culturas. Revista

Brasileira de Ciência do Solo, v.23, n.4, p.997-1003, 1999.

DURIGAN, G.; SILVEIRA, É. R. Recomposição da mata ciliar em domínio de cerrado, Assis, SP.

Scientia Forestalis, n.56, p.135-144, 1999.

DURIGAN, G. Restauração da cobertura vegetal em região de domínio do cerrado. In: GALVÃO, A. P. M.; PORFÍRIO, S. V. (Eds.). Restauração florestal: fundamentos e estudos de caso. Colombo: Embrapa Florestas, 2005. p.103-118.

\section{EMPRESA BRASILEIRA DE PESQUISA} AGROPECUARIA - Embrapa. Sistema brasileiro de classificação de solos. Rio de Janeiro: Embrapa/CNPSO, 1999. 412p.

FERREIRA, D. F. SISVAR. Lavras:

Departamento de Ciências Exatas, Universidade Federal de Lavras, 2004.

FERREIRA, R. L. C. et al. Deposição e acúmulo de matéria seca e nutrientes em serapilheira em um bosque de sabiá (Mimosa caesalpiniifolia Benth.). Revista Árvore, v.31, n.1, p.7-21, 2007.

GONÇALVES, J. L. M. Recomendações de adubação para Eucalyptus, Pinus e espécies típicas de Mata Atlântica. Piracicaba: Universidade de São Paulo - ESALQ, 1995. 15p. (Documentos Florestais 15).
HARIDASAN, M. Solos de matas de galeria e nutrição mineral de espécies arbóreas em condições naturais. In: RIBEIRO, J. F (Ed.) Cerrado: matas de galeria. Planaltina: EmbrapaCPAC, 1998. p.19-28.

JACOMINE, P. K. T. Solos sob matas ciliares. In: RODRIGUES, R. R.; LEITÃO FILHO, H. F. (Eds.). Matas ciliares: conservação e recuperação. 2.ed. São Paulo: Universidade de São Paulo, 2004. p.27-31.

LEÃO, S. R. F. Potencial agrícola dos solos do Distrito Federal. In: PINTO, M. N. (Org.). Cerrado: caracterização, ocupação e perspectivas. 2.ed. Brasília: UnB, 1994. p.455-468.

LOPES, A. S. "Solos sob cerrados": características, propriedades e manejo. Piracicaba: Instituto da Potassa \& Fosfato: Instituto Internacional da Potassa, 1984. 162p.

MARTINS, S. V. Recuperação de matas ciliares. ViçosaMG: Aprenda Fácil, 2001. 143p.

PINHEIRO, R. A.; FISCH, S. T. V.; ALMEIDA, A. A cobertura vegetal e as características do solo em área de extração de areia. Revista de

Biociências, v.10, n.3, p.103-110, 2004.

RAIJ, B.van. et al. (Eds.). Recomendações de adubação e calagem para o Estado de São Paulo. 2.ed. Campinas, Instituto Agronômico e Fundação IAC, 1996. 285p. (Boletim Técnico, 100).

RAIJ, B.van.; QUAGGIO, J.A. Métodos de análises de solo para fins de fertilidade. Campinas: Instituto Agronômico, de Campinas, 1983. 31p. (Boletim Técnico, 81).

REZENDE, A. V. Importância das matas de galeria: manutenção e recuperação. In: RIBEIRO, J.F (Ed.). Cerrado: matas de galeria. Planaltina: EmbrapaCPAC, 1998. p.1-16.

RODRIGUES, L. A. et al. Efeitos de solos e topografia sobre a distribuição de espécies arbóreas em um fragmento de floresta estacional semidecidual, em Luminárias, MG. Revista Árvore, v.31, n.1. p.25-35, 2007.

SCOTT, A. J.; KNOTT, M. A cluster analysis method for grouping means in the analysis of variance. Biometrics, v.30, n.3, p.507-512, 1974.

Revista Árvore, Viçosa-MG, v.35, n.1, p.97-106, 2011 
SILVA, P. P. V. Sistema agroflorestais para recuperação de mata ciliares em

Piracicaba, SP. 2002. 98f. Dissertação

(Mestrado em Ciências Florestais) - Universidade de São Paulo. Escola Superior de Agricultura "Luiz de Queiroz”, Piracicaba, 2002.
SOUZA, Z. M. Propriedades físicas e químicas de um Latossolo Vermelh-Escuro de Selvíria (MS) sob diferentes usos e manejos. 2000. 127f. Dissertação (Mestrado em Agronomia) - Faculdade de Engenharia de Ilha Solteira, Universidade Estadual Paulista, Ilha Solteira, 2000. 